\title{
Current treatment landscape for patients with locally recurrent inoperable or metastatic triple-negative breast cancer: a systematic literature review
}

\author{
Claire H. Li ${ }^{\dagger}$, Vassiliki Karantza, Gursel Aktan and Mallika Lala ${ }^{* \dagger}$
}

\begin{abstract}
Background: Metastatic triple-negative breast cancer (mTNBC), an aggressive histological subtype, has poor prognosis. Chemotherapy remains standard of care for mTNBC, although no agent has been specifically approved for this breast cancer subtype. Instead, chemotherapies approved for metastatic breast cancer (MBC) are used for mTNBC (National Comprehensive Cancer Network Guidelines [NCCN] v1.2019). Atezolizumab in combination with nab-paclitaxel was recently approved for programmed death-ligand 1 (PD-L1)-positive locally advanced or metastatic TNBC. Published historical data were reviewed to characterize the efficacy of NCCN-recommended (v1.2016) agents as first-line (1L) and second-line or later (2L+) treatment for patients with locally recurrent inoperable or metastatic TNBC (collectively termed mTNBC herein).
\end{abstract}

Methods: A systematic literature review was performed, examining clinical efficacy of therapies for mTNBC based on NCCN v1.2016 guideline recommendations. Data from 13 studies, either published retrospective mTNBC subgroup analyses based on phase III trials in MBC or phase II trials in $\mathrm{MTNBC}$, were included.

Results: A meta-analysis of mTNBC subgroups from three phase III trials in $1 \mathrm{~L} \mathrm{MBC}$ reported pooled objective response rate (ORR) of 23\%, median overall survival (OS) of 17.5 months, and median progression-free survival (PFS) of 5.4 months with single-agent chemotherapy. In two subgroup analyses from a phase III study and a phase II trial ( $n=40$ each), median duration of response (DOR) to $1 \mathrm{~L}$ chemotherapy for mTNBC was 4.4-6.6 months; therefore, responses were not durable. A meta-analysis of seven cohorts showed the pooled ORR for $2 \mathrm{~L}+$ chemotherapy was $11 \%$ (95\% Cl, 9-14\%). Median DOR to 2L+ chemotherapy in mTNBC was also limited (4.2-5.9 months) per two subgroup analyses from a phase III study. No combination chemotherapy regimens recommended by NCCN v1.2016 for treatment of MBC showed superior OS to single agents.

Conclusions: Chemotherapies have limited effectiveness and are associated with unfavorable toxicity profiles, highlighting a considerable unmet medical need for improved therapeutic options in mTNBC. In addition to the recently approved combination of atezolizumab and nab-paclitaxel for PD-L1-positive MTNBC, new treatments resulting in durable clinical responses, prolonged survival, and manageable safety profile would greatly benefit patients with $\mathrm{mTNBC}$.

Keywords: Metastatic triple-negative breast cancer, Chemotherapy, Immune checkpoint inhibitor, PARP inhibitor

\footnotetext{
* Correspondence: mallika.lala@merck.com

${ }^{\dagger}$ Claire H. Li and Mallika Lala contributed equally to this work.

Merck \& Co., Inc., Kenilworth, NJ, USA
}

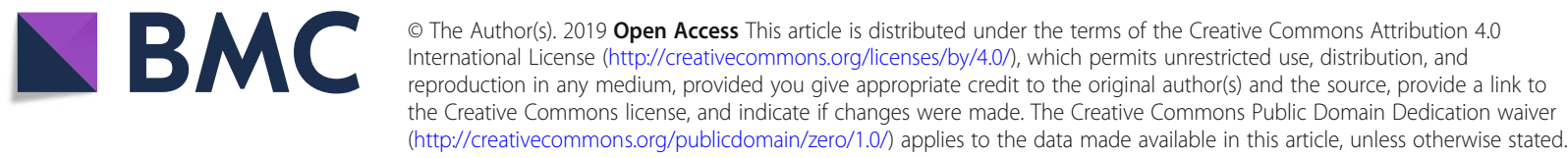




\section{Introduction}

Breast cancer (BC) is the most common malignant neoplasm in females; an estimated 266,120 new diagnoses and 40,920 related deaths occurred in the USA in 2018 [1]. Approximately $10-20 \%$ of BCs do not express estrogen and progesterone receptors and lack amplification/ overexpression of the human epidermal growth factor 2 receptor (HER2) [2-4]; therefore, they are known as triple-negative breast cancers (TNBCs) and constitute an aggressive histologic subtype. In patients with locally recurrent inoperable or metastatic disease (collectively referred to as mTNBC in this article), treatment options have primarily been chemotherapies based on recommended therapeutic approaches (National Comprehensive Cancer Network [NCCN] v1.2019 guidelines and the European School of Oncology-European Society for Medical Oncology [ESO-ESMO] 2018 guidelines) for metastatic breast cancer $(\mathrm{MBC})[5,6]$. In particular, anthracyclines, taxanes, capecitabine, and more recently, eribulin are commonly used as monotherapy or in combination with other agents and as standard/control arms in registration trials of new/investigational agents for TNBC. Anthracyclines and taxanes are both recommended, unless contraindicated, as first-line (1L) treatments for patients who have not previously received these agents as neoadjuvant or adjuvant treatment $[5,6]$. The efficacy of anthracyclines in $\mathrm{mTNBC}$ has been inferred from earlier studies that involved patients with MBC in which the TNBC subpopulation was not distinctly defined (mostly because of the absence of HER2 status reporting) [7]. Compared with taxanes, anthracyclines have not demonstrated overall survival (OS) benefit in mTNBC [8]. Because data on the effectiveness of anthracyclines are not available in the mTNBC population and anthracyclines and taxanes are generally considered similarly effective, anthracyclines are not discussed further in this review.

Overall prognosis for patients with mTNBC is worse than for the other BC subtypes, and more effective therapeutic options are needed. In a pooled analysis of two phase III trials in $\mathrm{MBC}$, inferior outcomes were reported with $1 \mathrm{~L}$ or later line physician choice of chemotherapy for patients with mTNBC than for the overall MBC population [9]. Chemotherapies are generally associated with unfavorable adverse events (AEs), more so in combination, that can lead to treatment discontinuation. Because combination regimens have not prolonged OS compared with monotherapies, the approach recommended by the NCCN v1.2019/ESO-ESMO 2018 guidelines $[5,6]$ for the treatment of $\mathrm{MBC}$ (including mTNBC) remains sequential use of single-agent chemotherapy. Based on recent evidence that atezolizumab plus nab-paclitaxel improves progression-free survival (PFS), this combination was recently granted accelerated approval by the US Food and Drug Administration (FDA) in patients with programmed death-ligand 1 (PDL1)-positive (immune cell score, IC 1+) TNBC [5, 10, 11]. In general, clinical trials conducted only in patients with mTNBC are limited. No phase III trials have been conducted to specifically evaluate single agents as treatment for mTNBC in any line of therapy, and only a limited number of phase III trials have been conducted to evaluate combination therapies in the mTNBC population. The purpose of the current evidence synthesis was to systematically characterize the efficacy of commonly used chemotherapies, defined herein to be agents recommended in the NCCN v1.2016 guidelines (which were current at the time of this analysis) [12], as $1 \mathrm{~L}$ and second-line or later $(2 \mathrm{~L}+)$ treatment for patients with mTNBC, thereby providing a summary of available historical data.

\section{Methods \\ Systematic review}

A systematic review of the literature was conducted to synthesize objective response rate (ORR), duration of response (DOR), PFS, and OS of commonly used chemotherapies as $1 \mathrm{~L}$ or $2 \mathrm{~L}+$ treatment for patients with mTNBC. Commonly used chemotherapies were defined as agents recommended in the NCCN v1.2016 guidelines for the treatment of MBC (including $\mathrm{mTNBC}$ ) as single agents or combinations thereof, including the combination of paclitaxel and bevacizumab [12]. Clinical trial results published in English between January 1, 1996, and August 21, 2016, were identified by searching the PubMed (MEDLINE), Cochrane, and Embase databases (Additional file 1: Table S1, Additional file 2: Table S2, Additional file 3: Table S3). Identified publications were then manually screened for inclusion. Reports of phase III trials in either mTNBC or MBC (with mTNBC subgroup outcomes) populations, recent (2010 and later) phase II trials in mTNBC-only populations, and retrospective or metaanalyses of mTNBC subgroups based on phase III MBC trials were included. Details of the search inclusion and exclusion criteria are presented in Fig. 1. Studies published after 21 August 2016 were evaluated separately for relevance based on recent guideline updates and were included for completeness [10, 14-19].

\section{Study selection}

There was substantial heterogeneity in the inclusion of $1 \mathrm{~L}$ and $2 \mathrm{~L}+$ populations, between and within identified studies, with many studies including mixed patient populations in terms of prior therapy and current line of treatment. Studies were first classified by line of treatment ( $1 \mathrm{~L}, 2 \mathrm{~L}+$, mixed line). Only those that reported clinical efficacy outcomes in mTNBC populations in which the majority of patients $(\geq 80 \%)$ were given $1 \mathrm{~L}$ or 


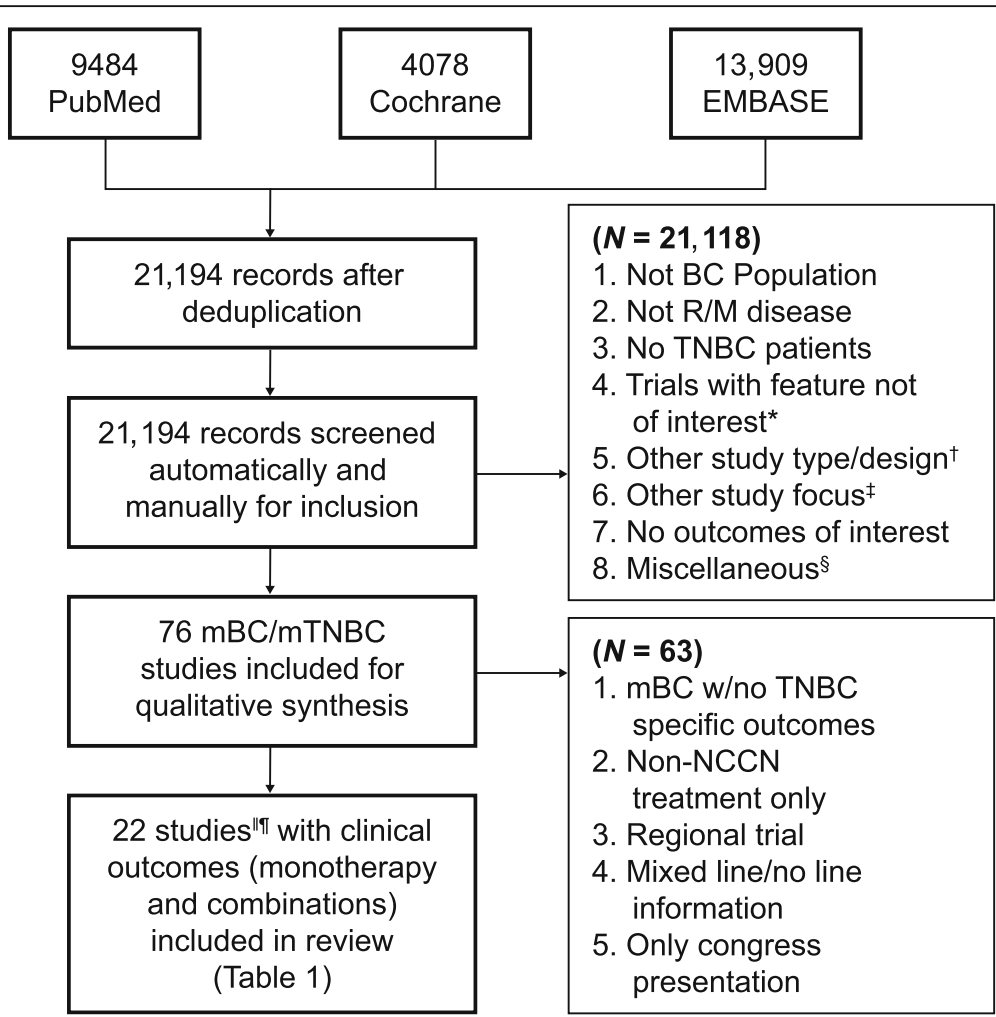

Fig. 1 Study selection process for the systematic literature review and meta-analysis of breast cancer (BC). *Exclusions include not phase II, not phase III or phase II with triple-negative breast cancer (TNBC) focus, phase II not TNBC focus, not phase II or phase III, and not TNBC focus phase II/I. 'Exclusions include review articles, other study types, not recurrent/metastatic (R/M) of phase III/I data, and not TNBC-specific R/M. ${ }^{\ddagger}$ Exclusions include non-cancer outcomes focus, only quality-of-life data, study protocol, surgical intervention, model development, and only AE data. SExclusions include other language, older report of the same study, and reference unavailable. "Results from one study (phase III trial, study 301) based on internal communication with sponsor (Eisai); not published results. 'Results from Twelves et al.'s [9] and Pivot et al.'s [13] studies are both included based on the reported different treatment line outcomes

$2 \mathrm{~L}+$ treatment with chemotherapy, as single-agent and in combination regimens, were included in the review. Reports of clinical trials that were conducted regionally (limited to one geographic location) in a non-White population and reports that were limited to presentation at a congress but not published were excluded from the review.

\section{Data analysis and meta-analysis}

Clinical outcomes, including ORR and OS, were qualitatively represented by monotherapy as $1 \mathrm{~L}$ and $2 \mathrm{~L}+$ therapy, as shown in Figs. 3 and 4. Meta-analyses were performed to synthesize the pooled ORRs for singleagent chemotherapy among studies of $2 \mathrm{~L}+$ treatment. Inverse-variance fixed-effects and random-effects metaanalyses were explored. A DerSimonian and Laird random-effects model was used to account for betweentrial heterogeneity; this model assumes that the true treatment effects of the included studies follow a distribution around an overall mean [20]. The sample size, ORR, 95\% confidence interval $(95 \% \mathrm{CI})$ for each treatment and study, and pooled ORR (95\% CI) are presented as forest plots, per PRISMA guidelines [21]. The ORRs were re-estimated using the all-patients-as-treated (APaT) population to ensure common definition across studies. The ORR proportions were transformed to a logit scale to calculate $95 \% \mathrm{CIs}$ and then transformed back to proportions.

\section{Data sources and software}

The PubMed, Cochrane, and Embase databases were searched for eligible studies/publications; Microsoft Office Excel (Redmond, WA, USA) was used to synthesize study records. As necessary, trial eligibility criteria were compared against the criteria listed on ClinicalTrials.gov. Meta-analyses of ORR were conducted in $\mathrm{R}$ (version 3.1.3) using the metafor package [22]. Qualitative graphical analyses of ORR, DOR, OS, and PFS across identified trials were performed using $\mathrm{R}$ (version 3.2.5).

\section{Results}

A total of 21,194 references were collected from combined literature searches of PubMed, Cochrane, and Embase databases after filtering duplicate records 
(Fig. 1). From those references, 76 studies complied with the key inclusion criteria from qualitative synthesis. Of these 76 trials, 63 were excluded, as described in the "Results" section (Fig. 1). Finally, 21 studies that reported clinical outcomes of interest with chemotherapies for patients with mTNBC were reviewed in detail and are reported herein.

A summary of study outcomes of all included studies is given in Table 1. ORRs based on the APaT populations were calculated to facilitate comparisons across studies. ORRs were re-estimated based on the APaT population (i.e., number of responders divided by number of patients composing the APaT population for studies in which ORR was reported based on the evaluable or intention-to-treat population [ITT]). The clinical outcomes for patients with mTNBC treated with NCCNrecommended (v1.2016) agents $[6,12]$ as either $1 \mathrm{~L}$ or $2 \mathrm{~L}+$ therapy were further separated based on whether the investigation therapy was monotherapy or combination therapy (Table 1).

\section{Description of the study outcomes with NCCN- recommended (v1.2016) agents \\ Monotherapy}

No published data from randomized controlled phase III trials with single-agent chemotherapy as $1 \mathrm{~L}$ or later lines of treatment for mTNBC were found. Thirteen published reports (disregarding congress presentations) of retrospective subgroup analyses in patients with mTNBC based on phase III trials in MBC or phase II trials in mTNBC with limited sample size were identified, considering all lines of treatment. Of these, six studies reported clinical efficacy outcomes in the $1 \mathrm{~L}$ mTNBC patient population, as summarized in Table $1[24,25$, 27, 28, 32]. Treatments included capecitabine, taxanes (docetaxel, paclitaxel), eribulin, ixabepilone, or platinum (carboplatin, cisplatin). Furthermore, nine studies, also summarized in Table 1, reported clinical efficacy outcomes in the $2 \mathrm{~L}+\mathrm{mTNBC}$ patient population; treatments included capecitabine, carboplatin, cisplatin, or eribulin $[9,13,23,25-27,30,31,33]$.

First-line Among the six studies on $1 \mathrm{~L}$ treatment, five had published outcomes [24, 25, 27, 28, 32]. For one study (phase III trial, study 301), clinical outcomes for the mTNBC subgroup were available via internal communication. Notably, a meta-analysis of the mTNBC subgroups from three phase III trials in 1L MBC [28] reported a pooled ORR of $23 \%$ and median OS of 17.5 months. In trial 301, which compared eribulin with capecitabine for the treatment of $\mathrm{MBC}$, in the mTNBC subgroup, ORR for $1 \mathrm{~L}$ eribulin and capecitabine was $10 \%$ and $12 \%$, respectively.
In addition, four phase II trials conducted to investigate single-agent chemotherapies for mTNBC with sample sizes of 28-69 were identified; the reported ORR ranged from 12 to $30 \%$, and a median OS of 13.1 months was reported in only one [24] of these phase II trials. In studies that reported response duration (two subgroup analyses from a phase III study (study 301 ) and one phase II trial, all limited in sample size [ $n=40$ each]), the median DOR to $1 \mathrm{~L}$ chemotherapy in $\mathrm{mTNBC}$ ranged from 4.4 to 6.6 months (Table 1) [32]. Qualitative analyses of the sample sizes, ORR, and OS are shown graphically in Figs. 3b and $4 \mathrm{~b}$.

Second-line or later Among the nine studies on $2 \mathrm{~L}+$ treatment, seven phase III studies in MBC reported clinical efficacy outcomes for mTNBC subgroups $[9,13,23$, $26,30,31,33]$. In these studies, ORR ranged from 9 to 18\%; median OS, from 8.1 to 15.2 months. The median DOR to $2 \mathrm{~L}+$ chemotherapy in mTNBC was only available from two subgroup analyses of a phase III study (study 301) and ranged from 4.2 to 5.9 months. Two additional phase II studies reported ORR of $6 \%$ and $11.8 \%$ with platinum (cisplatin/carboplatin) [25, 27]. A meta-analysis of ORR reported for seven cohorts from six of these studies (mTNBC subgroup analyses from five phase III trials in $\mathrm{MBC}$ and two phase II trials in mTNBC) resulted in a pooled ORR of $11 \%$ (95\% CI, 914\%) for chemotherapy in Fig. 2. Qualitative analyses of the sample sizes, ORR, and OS are shown graphically in Figs. 3a and 4a.

\section{Combination therapy}

Eleven published clinical studies reported efficacy outcomes in patients with mTNBC treated with NCCNrecommended (v1.2016) combination regimens [6, 12], either as chemotherapy-only regimens or in combination with bevacizumab (Table 1) [28, 30, 31, 34-41]. Only one phase III trial conducted specifically in the mTNBC population was identified, which evaluated the combination of gemcitabine, carboplatin, and iniparib/placebo as $1 \mathrm{~L}$-third-line (3L) treatment [40]. The overall reported ORR was $32 \%$, and median OS was 11.1 months. In the $1 \mathrm{~L}$ setting $(n=149)$, median PFS and OS were 4.6 and 13.9 months, respectively, whereas in the $2 \mathrm{~L}+$ setting $(n=109)$, median PFS and OS were 2.9 and 8.1 months, respectively.

First-line In addition to monotherapy, as described previously herein, the meta-analysis of the mTNBC subgroups from three phase III trials in $1 \mathrm{~L} \mathrm{MBC} \mathrm{[28]} \mathrm{also} \mathrm{reported}$ pooled outcomes for chemotherapy and bevacizumab combinations, including the NCCN-recommended (v1.2016) paclitaxel + bevacizumab regimen. In these studies, ORR was $42 \%$; median OS, 18.9 months. Furthermore, two 
Table 1 Study outcomes of TNBC patients treated with NCCN-recommended (v1.2016) monotherapy and combination therapy

\begin{tabular}{|c|c|c|c|c|c|c|c|c|c|c|c|c|}
\hline Author & $\begin{array}{l}\text { Study } \\
\text { description }\end{array}$ & Treatment & $\begin{array}{l}\text { Patient } \\
\text { population }\end{array}$ & $\begin{array}{l}\% \\
1 \mathrm{~L}\end{array}$ & $\begin{array}{l}\% \\
2 L\end{array}$ & $\begin{array}{l}\% \\
3 \mathrm{~L}+\end{array}$ & $N^{\ddagger}$ & $\begin{array}{l}\mathrm{ORR}^{\ddagger} \\
\%\end{array}$ & $\begin{array}{l}\text { DOR, } \\
\text { months }\end{array}$ & $\begin{array}{l}\text { PFS, } \\
\text { months }\end{array}$ & $\begin{array}{l}\text { OS, } \\
\text { months }\end{array}$ & $\begin{array}{l}\% \\
\text { TNBC } \\
\text { patients }\end{array}$ \\
\hline \multicolumn{13}{|c|}{ NCCN-recommended (v1.2016) monotherapies } \\
\hline Aftimos et al. [23] & $\begin{array}{l}\text { Retrospective } \\
\text { phase III sub- } \\
\text { group analysis }\end{array}$ & Eri & $\begin{array}{l}2 \mathrm{~L}+\mathrm{MBC} \\
\mathrm{w} / \mathrm{mTNBC}\end{array}$ & 0 & 1 & 00 & 22 & 18 & $N / R$ & $N / R$ & $N / R$ & 17 \\
\hline Awada et al. [24] & Phase II & Pac & $1 \mathrm{~L} \mathrm{mTNBC}$ & 100 & 0 & 0 & 28 & 28.6 & $N / R$ & 3.5 & 13.1 & 100 \\
\hline \multirow[t]{3}{*}{ Baselga et al. [25] } & Phase II & Cis & $\begin{array}{l}1 \mathrm{~L}-2 \mathrm{~L} \\
\text { mTNBC }\end{array}$ & 72 & 28 & 0 & 60 & 10 & $N / R$ & 1.5 & 9.4 & 100 \\
\hline & Phase II & Cis & $1 \mathrm{~L} \mathrm{mTNBC}$ & & & & 42 & 12 & $N / R$ & $N / R$ & $N / R$ & 100 \\
\hline & Phase II & Cis & $2 \mathrm{~L} \mathrm{mTNBC}$ & & & & 16 & 6 & $N / R$ & $N / R$ & $N / R$ & 100 \\
\hline Brufsky et al. [26] & RIBBON-2 & $\begin{array}{l}\text { Physician's } \\
\text { choice chemo }\end{array}$ & $\begin{array}{l}\text { 2L MBC } \\
\text { W/mTNBC }\end{array}$ & 0 & 100 & 0 & 47 & 18 & $N / R$ & 2.7 & 12.6 & 21 \\
\hline \multirow[t]{3}{*}{ Isakoff et al. [27] } & Phase II & Car/cis & $\begin{array}{l}1 \mathrm{~L}-2 \mathrm{~L} \\
\text { mTNBC }\end{array}$ & 80 & 20 & 0 & 86 & 25.6 & $N / R$ & 2.9 & 11 & 100 \\
\hline & Phase II & $\mathrm{Car} / \mathrm{cis}$ & $1 \mathrm{~L} \mathrm{mTNBC}$ & & & & 69 & 29 & $N / R$ & $N / R$ & $N / R$ & 100 \\
\hline & Phase II & Car/cis & $2 \mathrm{~L}$ mTNBC & & & & 17 & 11.8 & $N / R$ & $N / R$ & $N / R$ & 100 \\
\hline Miles et al. [28] & $\begin{array}{l}\text { RIBBON-1 + } \\
\text { AVADO + E2100 } \\
\text { pooled } \\
\text { subgroup }\end{array}$ & Cap/doc/pac & $\begin{array}{l}1 \mathrm{~L} \mathrm{MBC} \\
\mathrm{w} / \mathrm{mTNBC}\end{array}$ & 100 & 0 & 0 & 255 & 23.3 & $N / R$ & 5.4 & 17.5 & 26 \\
\hline Perez et al. [29] & BEACON & $\begin{array}{l}\text { Physician's } \\
\text { choice chemo }\end{array}$ & $\begin{array}{l}3 L+M B C \\
w / m T N B C\end{array}$ & 0 & 0 & 100 & 117 & $N / R$ & $N / R$ & $N / R$ & 8.8 & 28 \\
\hline Pivot et al. [30] & $\begin{array}{l}\text { Prespecified } \\
\text { phase III } \\
\text { subgroup }\end{array}$ & Cap & $\begin{array}{l}1 \mathrm{~L}-3 \mathrm{~L}+\mathrm{MBC} \\
\mathrm{w} / \mathrm{mTNBC}\end{array}$ & 9 & 49 & 43 & 96 & 9 & $N / R$ & 2.1 & $N / R$ & 25 \\
\hline Sparano et al. [31] & Phase III & Cap & $\begin{array}{l}1 \mathrm{~L}-3 \mathrm{~L}+\mathrm{MBC} \\
\mathrm{w} / \mathrm{mTNBC}\end{array}$ & 19 & 63 & 18 & 134 & $\mathrm{~N} / \mathrm{R}$ & $N / R$ & 1.81 & $N / R$ & 22 \\
\hline \multirow[t]{4}{*}{ Study $301^{\dagger}$} & $\begin{array}{l}\text { Phase III } \\
\text { subgroup }\end{array}$ & Cap & $\begin{array}{l}1 \mathrm{~L} \mathrm{MBC} \\
\mathrm{w} / \mathrm{mTNBC}\end{array}$ & & & & 40 & 12 & 4.4 & $N / R$ & 9.9 & 24.5 \\
\hline & & Eri & $\begin{array}{l}1 \mathrm{LMBC} \\
\mathrm{w} / \mathrm{mTNBC}\end{array}$ & & & & 40 & 10.4 & 6.6 & $N / R$ & 13.1 & 27.1 \\
\hline & $\begin{array}{l}\text { Phase III } \\
\text { subgroup }\end{array}$ & Cap & $\begin{array}{l}2 \mathrm{~L}+\mathrm{MBC} \\
\mathrm{W} / \mathrm{mTNBC}\end{array}$ & & & & 96 & $\sim 10$ & 5.9 & 2.8 & 9.2 & 24.5 \\
\hline & & Eri & $\begin{array}{l}2 \mathrm{~L}+\mathrm{MBC} \\
\mathrm{w} / \mathrm{mTNBC}\end{array}$ & & & & 110 & $\sim 10$ & 4.2 & 3.4 & 15.2 & 27.1 \\
\hline Tredan et al. [32] & Phase II & Ixa & $1 \mathrm{~L} \mathrm{mTNBC}$ & 100 & 0 & 0 & 40 & 30 & 4.5 & 4.1 & $N / R$ & 100 \\
\hline \multirow[t]{2}{*}{$\begin{array}{l}\text { Twelves et al. [9] and Pivot } \\
\text { et al. [13] }\end{array}$} & $\begin{array}{l}\text { EMBRACE + } 301 \\
\text { pooled } \\
\text { subgroup }\end{array}$ & Eri & $\begin{array}{l}1 \mathrm{~L}-3 \mathrm{~L}+\mathrm{MBC} \\
\mathrm{w} / \mathrm{mTNBC}\end{array}$ & 11 & 27 & 62 & 243 & 12 & $N / R$ & 2.8 & 12.9 & 22.9 \\
\hline & $\begin{array}{l}\text { EMBRACE + } 301 \\
\text { pooled } \\
\text { subgroup }\end{array}$ & Eri & $\begin{array}{l}2 \mathrm{~L}+\mathrm{MBC} \\
\mathrm{W} / \mathrm{mTNBC}\end{array}$ & & & & 199 & 11 & $N / R$ & 2.8 & 12.4 & 22.9 \\
\hline \multirow[t]{2}{*}{$\begin{array}{l}\text { Twelves et al. [9] and Pivot } \\
\text { et al. [13] }\end{array}$} & $\begin{array}{l}\text { EMBRACE + } 301 \\
\text { pooled } \\
\text { subgroup }\end{array}$ & $\begin{array}{l}\text { Physician's } \\
\text { choice chemo }\end{array}$ & $\begin{array}{l}1 \mathrm{~L}-3 \mathrm{~L}+\mathrm{MBC} \\
\mathrm{w} / \mathrm{mTNBC}\end{array}$ & 13 & 37 & 50 & 185 & 10.3 & $N / R$ & 2.6 & 8.2 & 23.1 \\
\hline & $\begin{array}{l}\text { EMBRACE + } 301 \\
\text { pooled } \\
\text { subgroup }\end{array}$ & $\begin{array}{l}\text { Physician's } \\
\text { choice chemo }\end{array}$ & $\begin{array}{l}2 \mathrm{~L}+\mathrm{MBC} \\
\mathrm{W} / \mathrm{mTNBC}\end{array}$ & & & & 153 & 9 & $N / R$ & 2.5 & 8.1 & 23.1 \\
\hline von Minckwitz et al. [33] & TANIA & $\begin{array}{l}\text { Physician's } \\
\text { choice chemo }\end{array}$ & $\begin{array}{l}\text { 2L MBC } \\
\text { W/mTNBC }\end{array}$ & 0 & 100 & 0 & 57 & $N / R$ & $N / R$ & 2.1 & $N / R$ & 23 \\
\hline \multicolumn{13}{|c|}{ NCCN-v1.2016-recommended combination therapies } \\
\hline Brodowicz et al. $[34]^{\S}$ & TURANDOT & Bev+pac & $\begin{array}{l}1 \mathrm{~L} \mathrm{MBC} \\
\mathrm{W} / \mathrm{mTNBC}\end{array}$ & 100 & 0 & 0 & 63 & 49 & $N / R$ & 9 & 24.2 & 22 \\
\hline
\end{tabular}


Table 1 Study outcomes of TNBC patients treated with NCCN-recommended (v1.2016) monotherapy and combination therapy (Continued)

\begin{tabular}{|c|c|c|c|c|c|c|c|c|c|c|c|c|}
\hline Author & $\begin{array}{l}\text { Study } \\
\text { description }\end{array}$ & Treatment & $\begin{array}{l}\text { Patient } \\
\text { population }\end{array}$ & $\begin{array}{l}\% \\
1 \mathrm{~L}\end{array}$ & $\begin{array}{l}\% \\
2 \mathrm{~L}\end{array}$ & $\begin{array}{l}\% \\
3 L+\end{array}$ & $N^{\ddagger}$ & $\begin{array}{l}\mathrm{ORR}^{\ddagger} \\
\%\end{array}$ & $\begin{array}{l}\text { DOR, } \\
\text { months }\end{array}$ & $\begin{array}{l}\text { PFS, } \\
\text { months }\end{array}$ & $\begin{array}{l}\text { OS, } \\
\text { months }\end{array}$ & $\begin{array}{l}\% \\
\text { TNBC } \\
\text { patients }\end{array}$ \\
\hline \multirow[t]{3}{*}{ Dieras et al. [35] } & Phase II & Bev+pac & $\begin{array}{l}1 \mathrm{~L}-2 \mathrm{~L} \\
\mathrm{mTNBC}\end{array}$ & 81 & 19 & 0 & 61 & 47.53 & 7.5 & 7.2 & 17.4 & 100 \\
\hline & Phase II & Bev+pac & $1 \mathrm{~L}$ mTNBC & & & & 46 & $\mathrm{~N} / \mathrm{R}$ & $\mathrm{N} / \mathrm{R}$ & 7.2 & $N / R$ & 100 \\
\hline & Phase II & Bev+pac & $2 \mathrm{~L} \mathrm{mTNBC}$ & & & & 16 & $\mathrm{~N} / \mathrm{R}$ & $N / R$ & 7 & $N / R$ & 100 \\
\hline Fan et al. [36] & Phase II & Doc+cap & $1 \mathrm{LmTNBC}$ & 100 & 0 & 0 & 26 & 15.4 & $\mathrm{~N} / \mathrm{R}$ & 4.8 & 21.5 & 100 \\
\hline Halim et al. [37] & Phase II & Car+pac & $2 \mathrm{~L}+\mathrm{mTNBC}$ & 0 & & 00 & 50 & 60 & $\mathrm{~N} / \mathrm{R}$ & $N / R$ & $N / R$ & 100 \\
\hline \multirow[t]{3}{*}{ Li et al. [38] } & Phase II & Cap+cis & $\begin{array}{l}1 \mathrm{~L}-3 \mathrm{~L} \\
\mathrm{mTNBC}\end{array}$ & 84.9 & 12.1 & 3 & 33 & 63.6 & $\mathrm{~N} / \mathrm{R}$ & 8.2 & 17.8 & 100 \\
\hline & Phase II & Cap+cis & $1 \mathrm{~L}$ mTNBC & & & & 28 & 64.3 & $\mathrm{~N} / \mathrm{R}$ & 8.2 & 19.6 & 100 \\
\hline & Phase II & Cap+cis & $\begin{array}{l}2 \mathrm{~L}-3 \mathrm{~L} \\
\mathrm{mTNBC}\end{array}$ & & & & 5 & 60 & $N / R$ & 5.1 & 16.5 & 100 \\
\hline Liao et al. [39] & Phase II & Doc+cap & $1 \mathrm{~L} \mathrm{mTNBC}$ & 100 & 0 & 0 & 27 & 14.8 & $N / R$ & 4.9 & 21.5 & 100 \\
\hline Liao et al. [39] & Phase II & Vin+cap & $1 \mathrm{LmTNBC}$ & 100 & 0 & 0 & 18 & 27.8 & $N / R$ & 5.2 & 18.2 & 100 \\
\hline $\begin{array}{l}\text { Miles et al. [28]* (many } \\
\text { combinations with high } \\
\text { ORR-OS is still not much } \\
\text { higher) }\end{array}$ & $\begin{array}{l}\text { Pooled phase III } \\
\text { (E2100, AVADO, } \\
\text { RIBBON-1) }\end{array}$ & $\begin{array}{l}\text { Bev+(cap/doc/ } \\
\text { pac/nab-pac/ } \\
(\text { dox/epi/CP/ } \\
\text { FU)) }\end{array}$ & $\begin{array}{l}\text { 1L MBC } \\
w / m T N B C\end{array}$ & 100 & 0 & 0 & 360 & 42.3 & $\mathrm{~N} / \mathrm{R}$ & 8.1 & 18.9 & 25 \\
\hline \multirow[t]{3}{*}{ O'Shaughnessy et al. [40] } & Phase III & Gem+car & $\begin{array}{l}1 \mathrm{~L}-3 \mathrm{~L} \\
\text { mTNBC }\end{array}$ & 58 & 4 & 2 & 244 & 32 & $\mathrm{~N} / \mathrm{R}$ & 4.1 & 11.1 & 100 \\
\hline & Phase III & Gem+car & $1 \mathrm{~L} \mathrm{mTNBC}$ & & & & 149 & $\mathrm{~N} / \mathrm{R}$ & $\mathrm{N} / \mathrm{R}$ & 4.6 & 13.9 & 100 \\
\hline & Phase III & Gem+car & $\begin{array}{l}2 \mathrm{~L}-3 \mathrm{~L} \\
\mathrm{mTNBC}\end{array}$ & & & & 109 & $\mathrm{~N} / \mathrm{R}$ & $\mathrm{N} / \mathrm{R}$ & 2.9 & 8.1 & 100 \\
\hline Pivot et al. [30] & $\begin{array}{l}\text { Prespecified } \\
\text { phase III } \\
\text { subgroup }\end{array}$ & Ixa+cap & $\begin{array}{l}1 \mathrm{~L}-3 \mathrm{~L}+\mathrm{MBC} \\
\mathrm{w} / \mathrm{mTNBC}\end{array}$ & 7 & 48 & 45 & 91 & 27 & $\mathrm{~N} / \mathrm{R}$ & 4.1 & $N / R$ & 24.3 \\
\hline Rugo et al. [41] & Phase III & Bev+nab-pac & $\begin{array}{l}1 \mathrm{~L} \mathrm{MBC} \\
\mathrm{w} / \mathrm{mTNBC}\end{array}$ & 100 & 0 & 0 & 65 & $\mathrm{~N} / \mathrm{R}$ & $\mathrm{N} / \mathrm{R}$ & 7.4 & $N / R$ & 24 \\
\hline Rugo et al. [41] & Phase III & Bev+ixa & $\begin{array}{l}1 \mathrm{~L} \mathrm{MBC} \\
\mathrm{w} / \mathrm{mTNBC}\end{array}$ & 100 & 0 & 0 & 63 & $\mathrm{~N} / \mathrm{R}$ & $\mathrm{N} / \mathrm{R}$ & 5.6 & $\mathrm{~N} / \mathrm{R}$ & 26 \\
\hline Rugo et al. [41] & Phase III & Bev+pac & $\begin{array}{l}1 \mathrm{~L} \mathrm{MBC} \\
\mathrm{w} / \mathrm{mTNBC}\end{array}$ & 100 & 0 & 0 & 73 & $\mathrm{~N} / \mathrm{R}$ & $\mathrm{N} / \mathrm{R}$ & 6.5 & $N / R$ & 26 \\
\hline Sparano et al. [31] & Phase III & Ixa+cap & $\begin{array}{l}1 \mathrm{~L}-3 \mathrm{~L}+\mathrm{MBC} \\
\mathrm{w} / \mathrm{mTNBC}\end{array}$ & 20 & 61 & 19 & 122 & $\mathrm{~N} / \mathrm{R}$ & $\mathrm{N} / \mathrm{R}$ & 4.2 & $N / R$ & 20 \\
\hline
\end{tabular}

$1 L$ first-line, $2 L$ second-line, $3 L$ third-line, APaT all patients as treated, Bev bevacizumab, Cap capecitabine, Car carboplatin, chemo chemotherapy, Cis cisplatin, $C P$ cyclophosphamide, Doc docetaxel, Dox doxorubicin, Epi epirubicin, Eri eribulin, FU fluorouracil, Gem gemcitabine, Ixa ixabepilone, MBC metastatic breast cancer, ITNBC metastatic triple-negative breast cancer, N/R not reported, ORR objective response rate, Pac paclitaxel, TNBC triple-negative breast cancer, Vin vinorelbine *Paclitaxel in E2100, docetaxel in AVADO, capecitabine in one cohort of RIBBON-1, and either a single-agent taxane or an anthracycline-based combination in the second cohort of RIBBON-1. Of the total $n=255$ in the meta-analysis, $n=46$ belong to the taxane/anthracycline cohort of RIBBON-1; the number ( $<46$ ) of this subset of patients receiving anthracycline combination is unknown

${ }^{\dagger}$ Based on internal communication with trial sponsor (Eisai); not published results

${ }^{\ddagger} n$ and ORR based on APaT population

${ }^{\S} 2 \mathrm{~L}+\mathrm{MBC}$ with $\mathrm{mTNBC}$ outcomes are available in a separate study from Pivot et al. [13]

phase III trials in MBC included $20-25 \%$ patients with $\mathrm{mTNBC}$ and reported outcomes in their mTNBC subgroups $[28,41]$ In addition, four phase II trials were also identified that investigated combination regimens in $\mathrm{mTNBC}[35,36,38,39]$. Wide ranges of ORR (14.8-64.3\%), median PFS (4.8-8.2 months), and median OS (16.5-21.5 months) were reported across these studies, in which trial designs varied and sample sizes were small (18-46 patients).

Second-line or later Two phase III trials in patients with $\mathrm{MBC}$ reported outcomes for mTNBC subgroups treated with ixabepilone + capecitabine [30, 31]: median OS, 4.1-4.2 months, and ORR, 27\% (reported in one 


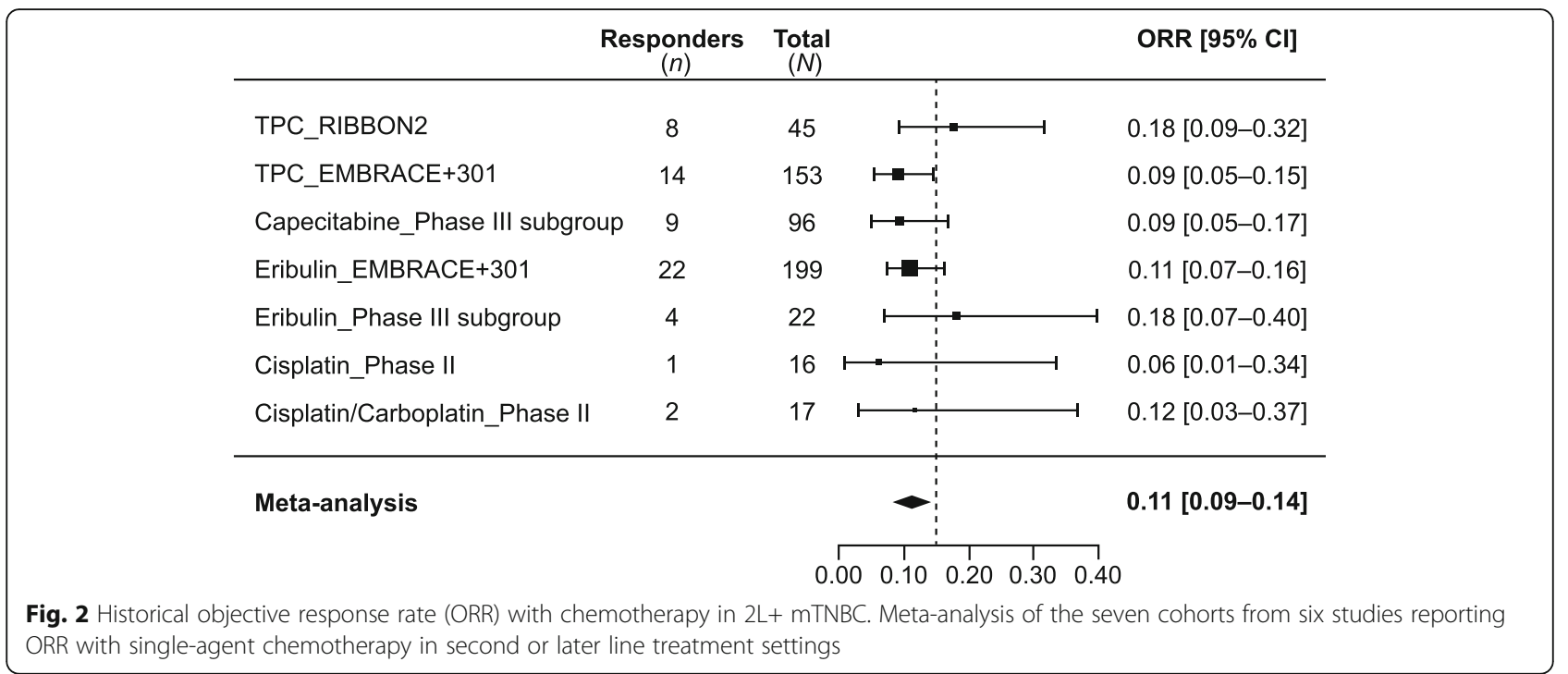

study). An additional phase II study conducted specifically in the $2 \mathrm{~L}+\mathrm{mTNBC}$ population was identified [37], which reported an ORR of $60 \%(n=50)$ with the paclitaxel + carboplatin combination.

\section{Discussion}

The current standard of care for management of mTNBC is chemotherapy, although no chemotherapy agent is specifically approved for TNBC. Instead, chemotherapies approved for MBC (all subtypes) are also used for the treatment of mTNBC (NCCN v1.2019 guidelines and ESO-ESMO guidelines 2018) [5,6]. With the advent of immunotherapies, atezolizumab in combination with nabpaclitaxel was recently approved for PD-L1-positive locally advanced or metastatic TNBC [11]. In general, the number of clinical trials conducted only in patients with mTNBC is limited. Considering NCCN-recommended (v1.2016) treatments, there were no published phase III trials to specifically evaluate single-agent chemotherapy in mTNBC in any line of treatment and only one phase III trial that evaluated combination chemotherapy in mTNBC [40]. The most commonly used treatments were taxanes, capecitabine, and, more recently, eribulin. These agents were also used as standard/ control arms in registration trials of new/investigational agents for mTNBC. The current systematic literature review was performed to determine effectiveness of treatments recommended for $\mathrm{MBC}$ in the NCCN v1.2016 guidelines, when used either as $1 \mathrm{~L}$ or $2 \mathrm{~L}+$ therapy for mTNBC $[6,12]$.

The wide range of ORRs (6-29\% with single agents; 14.8-64.3\% with combination regimens) to NCCNrecommended (v1.2016) therapies used as $1 \mathrm{~L}$ and $2 \mathrm{~L}+$ treatments for mTNBC highlights a need for more precise determination of the efficacy of these therapies to inform clinical practice. The data reviewed here suggest that the variability in ORRs was not fully attributed to differences in the effectiveness of available therapies. Small study size and heterogeneity in the characteristics of the enrolled patients (reflective of real-world clinical settings) were also significant factors. Moreover, the observed responses were generally not durable and did not necessarily translate to survival benefit. A key focus of this review was to summarize clinical outcomes taking into consideration the heterogeneity among studies caused by mixed-line patient populations and different therapeutic approaches. Historical studies identified via a systematic literature search were categorized based on the patient population being closer to $1 \mathrm{~L}$ or later line of treatment and the regimen being monotherapy or combination.

No published results of randomized controlled phase III trials in mTNBC in $1 \mathrm{~L}$ or later lines of treatment were found for single-agent chemotherapy. Published reports of either retrospective mTNBC subgroup analyses based on phase III trials in MBC or phase II trials in mTNBC with limited sample size were identified. These formed the evidence base in this review of historical data. A notable meta-analysis of the mTNBC subgroups from three phase III trials in $1 \mathrm{~L} \mathrm{MBC}$ [28] reported a pooled ORR of $23 \%$ and a median OS of 17.5 months with chemotherapy. Among available historical data, this study is regarded as the most relevant to efficacy outcomes from available $1 \mathrm{~L}$ treatments. The recent TNT trial also reported similar clinical outcomes (31-34\% ORRs and median OS of 12 months) in $2 \mathrm{~L}+$ mTNBC subgroups treated with carboplatin or docetaxel [19].

Although achieving clinical response is important, long-term clinical benefit of a treatment is linked 

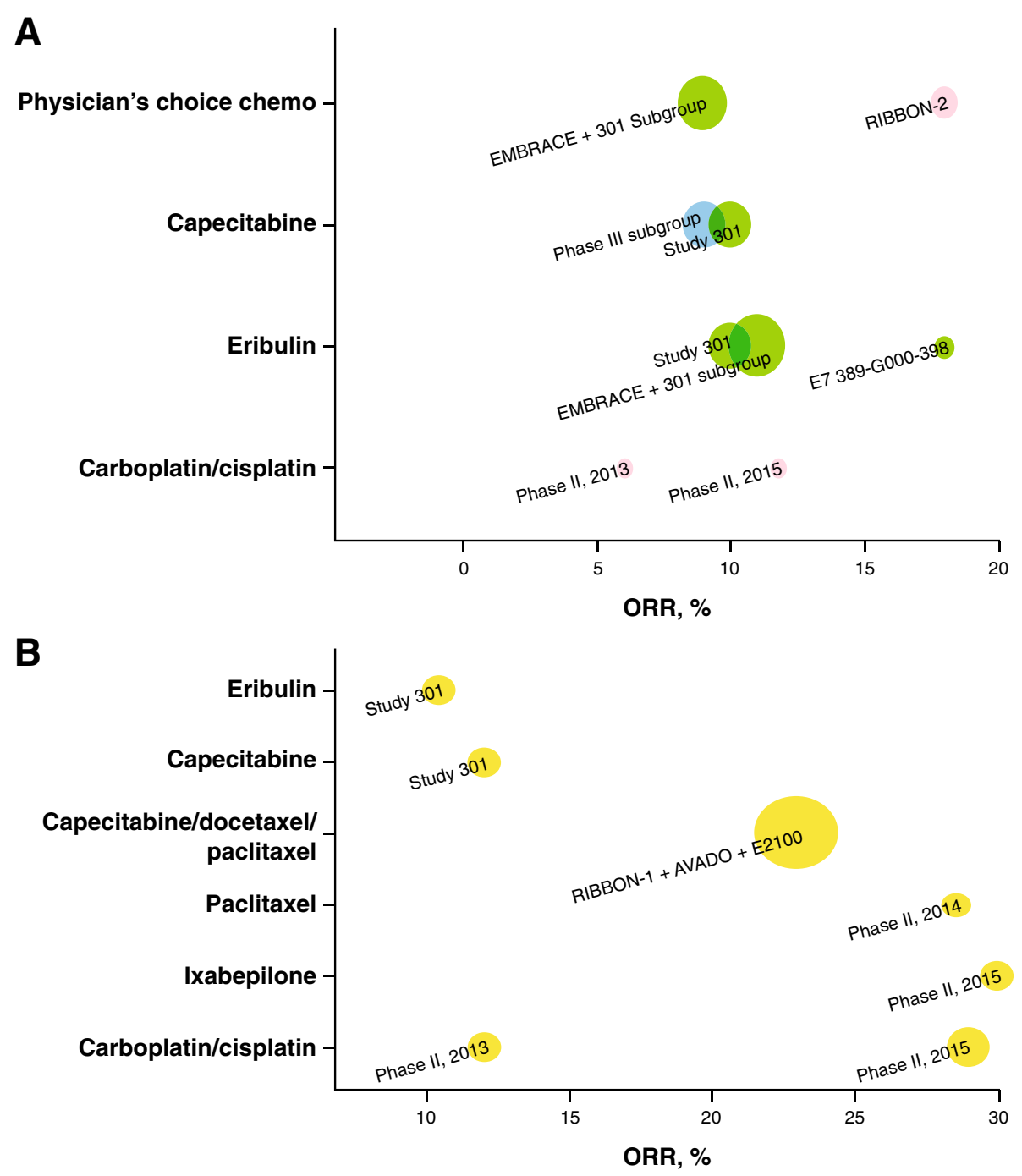

Fig. 3 Graphical representations of objective response rates (ORRs) for a trials of NCCN-recommended (v1.2016) second-line (2L) plus monotherapy (including studies mixed with first-line [1L]), and $\mathbf{b}$ trials of NCCN-recommended (v1.2016) first-line monotherapy; the size of the bubble is proportional to the study size (all-patients-as-treated population), and the color of the bubble indicates the line of therapy. Yellow $=1 \mathrm{~L}$, green $=2 \mathrm{~L}-3 \mathrm{~L}+$, pink $=2 \mathrm{~L}$, blue $=1 \mathrm{~L}-3 \mathrm{~L}+$ (including studies with $\leq 15 \% 1 \mathrm{~L}$ patients). Study 301 result is based on internal communication with trial sponsor (Eisai); not published results

with durability of the response. In two subgroup analyses from a phase III study (study 301) and one phase II trial [32], all limited in sample size $(n=40$ each), that reported response duration, median DOR to $1 \mathrm{~L}$ chemotherapy for $\mathrm{mTNBC}$ ranged from 4.4 to 6.6 months (Table 1), indicating that the responses were not durable. Considering later lines $(2 \mathrm{~L}+)$ of treatment, the efficacy of chemotherapies was lower than in the $1 \mathrm{~L}$ setting. Based on a meta-analysis of seven cohorts, the pooled ORR for chemotherapy was 11\% (95\% CI, 9-14\%) [13, 23, 25-27, 30]. Median DOR to $2 \mathrm{~L}+$ chemotherapy in mTNBC was also limited, ranging from 4.2 to 5.9 months, based on two subgroup analyses from a phase III study.
NCCN-recommended (v1.2016) combination regimens (including paclitaxel + bevacizumab) have not been proven superior to single-agent chemotherapy in terms of OS [5]. Only one global phase III trial of a combination regimen was found. This trial evaluated the gemcitabine, carboplatin, and iniparib/placebo combination as $1 \mathrm{~L}-3 \mathrm{~L}$ treatment for mTNBC [40]. Although the ORR to gemcitabine + carboplatin (32\%) exceeded clinical response rates seen with monotherapy, the combination did not prolong OS (median OS, 11.1 months in $1 \mathrm{~L}-3 \mathrm{~L}$ ) but was instead accompanied by higher toxicity (86\% of patients had AEs of grade 3 or higher toxicities, and 10\% discontinued treatment because of AEs). 


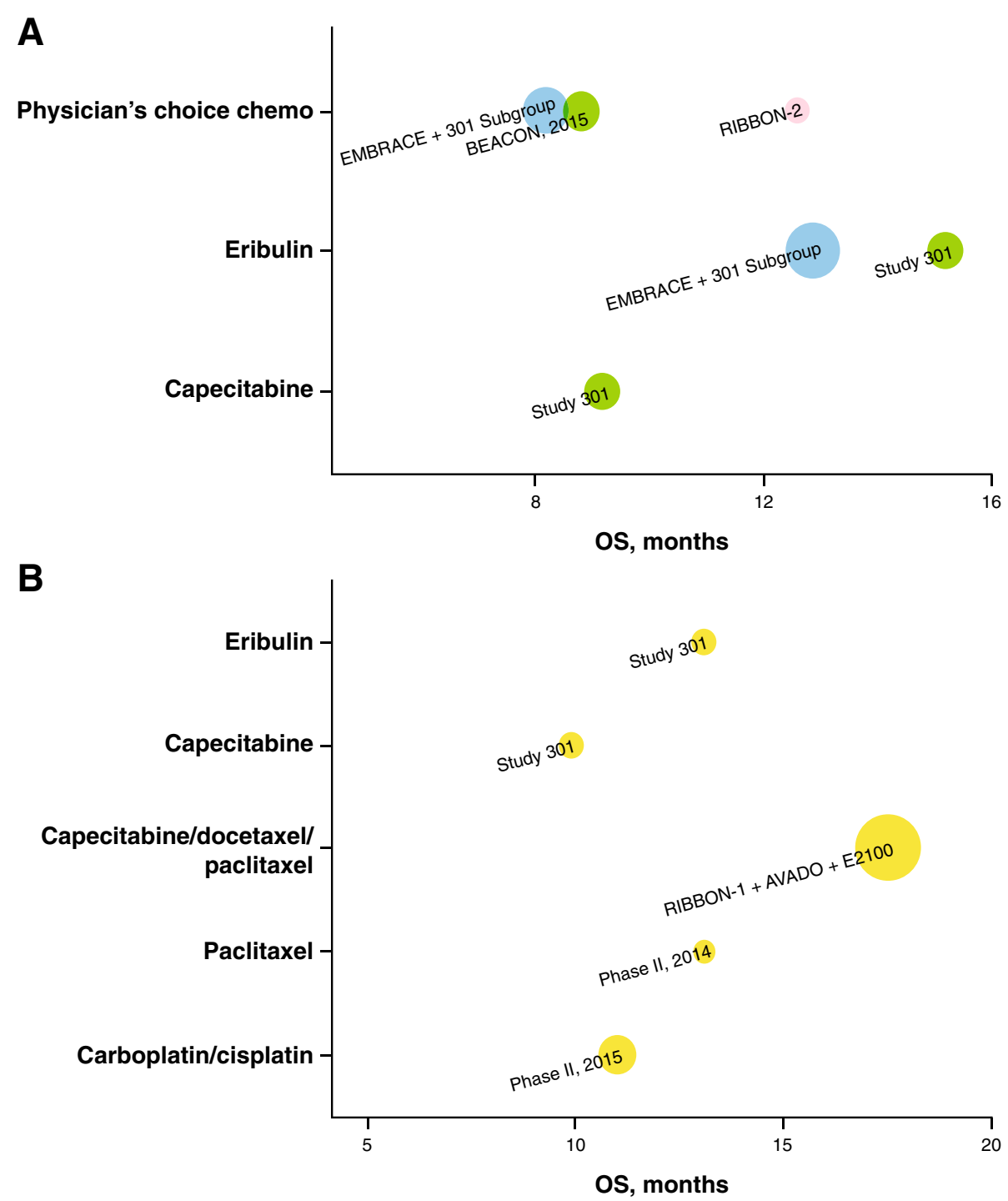

Fig. 4 Graphical representation of overall survival (OS) for a trials of NCCN-recommended (v1.2016) second-line (2L) plus monotherapy (including studies mixed with first-line [1L]), and $\mathbf{b}$ trials of NCCN-recommended (v1.2016) 1L monotherapy; the size of the bubble is proportional to the study size (all-patients-as-treated population), and the color of the bubble indicates the line of therapy. Yellow $=1 \mathrm{~L}$, green $=2 \mathrm{~L}-3 \mathrm{~L}+, \mathrm{pink}=2 \mathrm{~L}$, blue $=1 \mathrm{~L}-3 \mathrm{~L}+$ (including studies with $\leq 15 \% 1 \mathrm{~L}$ patients). Study 301 result is based on internal communication with trial sponsor (Eisai); not published results. OS from phase II 2015 study is based on a total of 86 patients, including $80 \% 1 \mathrm{~L}$ and 20\% 2L+ patients

In addition, the meta-analysis of the mTNBC subgroups from three phase III trials in $1 \mathrm{~L}$ MBC [28] also reported pooled outcomes for chemotherapy and bevacizumab combinations with an ORR of $42 \%$, which is higher than that for monotherapy, but a median OS (18.9 months) similar to that with monotherapy. The meta-analysis included patients treated with bevacizumab in combination with several chemotherapies, among which only the bevacizumab + paclitaxel combination is recommended by the NCCN v1.2016 guidelines. For $2 \mathrm{~L}+$ treatment of patients with $\mathrm{mTNBC}$, although the ORR for combination therapies was superior to that of monotherapy, survival (median OS, 4.1-4.2 months) was poor. The current NCCN v1.2019 guidelines continue to state that the recommended approach to treatment of mTNBC remains sequential use of single-agent chemotherapy, except in patients with PD-L1-positive mTNBC, for whom atezolizumab plus nab-paclitaxel may be considered [5].

Not only do commonly used chemotherapies for MBC result in short-lived responses in patients with mTNBC, but they are also associated with toxicity, such as myelosuppression and neuropathy, which can compromise quality of life and lead to early treatment discontinuation. A pooled analysis of two phase III trials in patients with $\mathrm{MBC}$ (including $\mathrm{mTNBC}$ ) receiving either single- 
agent physician's choice chemotherapy ( 70\% had capecitabine) or eribulin as $2 \mathrm{~L}+$ treatment reported inferior outcomes with $1 \mathrm{~L}$ or later-line chemotherapy for mTNBC than with overall MBC (ORR, $10.3 \%$ vs $16.4 \%$; OS, 8.2 vs 12.8 months; PFS, 2.6 vs 3.4 months for chemotherapy of physician's choice and ORR, $12.0 \%$ vs $14.9 \%$; OS, 12.9 vs 15.2 months; PFS, 2.8 vs 4.0 months for eribulin) [9]. The study also reported that $47 \%$ and $66 \%$ of patients, respectively, for physician choice chemotherapy and eribulin, had treatment-emergent AEs of grades 3 to 4 toxicity, with neutropenia and leukopenia being the most prominent, whereas discontinuations because of treatment-emergent AEs were $13.6 \%$ and $11.3 \%$, respectively [9]. The RIBBON-1 phase III trial [42] in patients with MBC (including $\mathrm{mTNBC}$ ) treated in the $1 \mathrm{~L}$ setting reported that $22 \%$ of participants in the capecitabine cohort and 38\% in the taxane cohort had AEs of grade 3-5 toxicity, with sensory neuropathy, neutropenia, and venous thromboembolism being the most common. The rates of discontinuations because of AEs were $11.9 \%$ and $7.8 \%$, respectively.

Specifically in the mTNBC population, AEs and treatment discontinuations because of toxicity have been reported in phase II studies as follows: ixabepilone $(1 \mathrm{~L}$ treatment), $45 \%$ of patients had AEs of grade $\geq 3$ toxicity (neutropenia and leukopenia most common) with 20\% discontinuations because of AEs [32]; paclitaxel (1L treatment), $10.7 \%$ discontinuations because of AEs [24]; and platinum (carboplatin/cisplatin, $1 \mathrm{~L}$ or $2 \mathrm{~L}$ treatment), $11.6 \%$ discontinuations because of AEs [27]. However, caution is required when drawing conclusions regarding the therapeutic index of different agents based on grade 3 or 4 toxicities, given that in some cases these toxicities may have minimal clinical consequence (e.g., grade 3 neutropenia in the absence of infection) whereas other chronic grade 2 toxicities may be intolerable or have a substantial impact on a patient's quality of life.

\section{New agents and agents in development}

New treatment options for mTNBC are emerging with the advent of immune checkpoint programmed death 1 (PD-1)/PD-L1 inhibitors, antibody drug conjugates (ADCs), and other immune therapies under investigation that could become essential for the treatment of mTNBC, either as monotherapy or in combination with other agents (Table 2). Targeted therapies and other chemotherapies under investigation, mostly in phase II studies, as $1 \mathrm{~L}$ and later lines of treatment for mTNBC are primarily single arm and often include mixed-line patient populations; hence, efficacy outcomes are challenging to interpret [24, 43-47].

\section{Immune checkpoint inhibitors}

Compared with nab-paclitaxel alone, atezolizumab in combination with nab-paclitaxel prolonged PFS in patients with mTNBC (ITT population: median PFS of 7.2 months vs 5.5 months; Table 2) in the IMpassion 130 trial. Median PFS among the subpopulation of that trial with PD-L1-positive tumors was 7.5 months in the atezolizumab group and 5.0 months in the placebo group [10]. PD-L1 positivity in that trial was determined using the Ventana PD-L1 [SP142] immunohistochemical assay (Roche Diagnostics USA) and was defined based on the percentage of PD-L1-expressing immune cells as a percentage of tumor area: IC3 ( $\geq 10 \%)$, IC2 $(\geq 5 \%$ to $<10 \%)$, IC1 $(\geq 1 \%$ and $<5 \%)$, and IC0 $(<1 \%)$. Combination atezolizumab plus nab-paclitaxel is now approved by the FDA for the treatment of PD-L1-positive (IC1+)

Table 2 Study outcomes of TNBC patients treated with NCCN-recommended (v1.2019) monotherapy in trials published since 2016

\begin{tabular}{|c|c|c|c|c|c|c|c|c|c|c|}
\hline Author & $\begin{array}{l}\text { Study } \\
\text { description }\end{array}$ & Treatment & $\begin{array}{l}\text { Patient } \\
\text { population }\end{array}$ & $\begin{array}{l}\% \\
1 \mathrm{~L}\end{array}$ & $\begin{array}{ll}\% & \% \\
2 \mathrm{~L} & 3 \mathrm{~L}+\end{array}$ & $N$ & $\begin{array}{l}\text { ORR } \\
\%\end{array}$ & $\begin{array}{l}\text { PFS } \\
\text { months }\end{array}$ & $\begin{array}{l}\text { OS } \\
\text { months }\end{array}$ & $\begin{array}{l}\% \mathrm{TNBC} \\
\text { patients }\end{array}$ \\
\hline \multirow[t]{2}{*}{ Tutt et al. [19] } & \multirow[t]{2}{*}{ Phase III TNT } & Car & $2 L+m T N B C$ & & \multirow[t]{2}{*}{100} & 59 & 31.4 & 3.1 & 12.4 & 100 \\
\hline & & Doc & & & & 64 & 34.0 & 4.5 & 12.3 & 100 \\
\hline \multirow{2}{*}{$\begin{array}{l}\text { Kim et al. [15] and Dent } \\
\text { et al. [14] }\end{array}$} & \multirow[t]{2}{*}{ Phase II LOTUS } & Pac+lpatasertib & $1 \mathrm{~L} \mathrm{mTNBC}$ & 100 & & 62 & NR & 6.2 & NR & 100 \\
\hline & & $\mathrm{Pac}$ & $1 \mathrm{~L} \mathrm{mTNBC}$ & 100 & & 62 & $N R$ & 4.9 & NR & 100 \\
\hline \multirow[t]{2}{*}{ Schmid et al. [10] } & \multirow[t]{2}{*}{$\begin{array}{l}\text { Phase III } \\
\text { IMpassion130 }\end{array}$} & $\begin{array}{l}\text { Atezolizumab plus } \\
\text { nab-paclitaxel }\end{array}$ & $1 \mathrm{~L} \mathrm{mTNBC}$ & 100 & & 451 & NR & 7.2 & 21.3 & 100 \\
\hline & & nab-paclitaxel & $1 \mathrm{~L} \mathrm{mTNBC}$ & 100 & & 451 & NR & 5.5 & 17.6 & 100 \\
\hline \multirow[t]{2}{*}{ Robson et al. $[17,18]$} & \multirow{2}{*}{$\begin{array}{l}\text { Phase III } \\
\text { OLYMPIAD }\end{array}$} & Olaparib & $1 \mathrm{~L}-2 \mathrm{~L} \mathrm{mBC}$ & & 100 & 205 & $\mathrm{NR}$ & 7.0 & 19.3 & 49.8 \\
\hline & & Physician's-Choice & $1 \mathrm{~L}-2 \mathrm{~L} \mathrm{mBC}$ & & & 97 & NR & 4.2 & 17.1 & 49.5 \\
\hline \multirow[t]{2}{*}{ Litton et al. [16] } & \multirow[t]{2}{*}{$\begin{array}{l}\text { Phase III } \\
\text { EMBRACA }\end{array}$} & Talazoparib & $\begin{array}{l}2 \mathrm{~L}+\text { locally } \\
\text { advanced } \mathrm{BC}\end{array}$ & & 100 & 287 & 62.6 & 8.6 & NR & 45.3 \\
\hline & & Physician's-Choice & $\begin{array}{l}2 \mathrm{~L}+\text { locally } \\
\text { advanced } \mathrm{BC}\end{array}$ & & & 144 & 27.2 & 5.6 & NR & 41.7 \\
\hline
\end{tabular}

$1 L$ first-line, $2 L$ second-line, $B C$ breast cancer, Car carboplatin, Doc docetaxel, $m T N B C$ metastatic triple-negative breast cancer, N/R not reported, ORR objective response rate, OS overall survival, PaC paclitaxel, PFS progression-free survival, TNBC triple-negative breast cancer 
mTNBC (with PD-L1 positivity established using an FDA-approved test) and is included in the most recent NCCN v1.2019 guidelines [5, 11]. Results of KEYNOTE355 , a phase III study of pembrolizumab in combination with one of (nab)-paclitaxel, gemcitabine, or carboplatin as $1 \mathrm{~L}$ therapy for $\mathrm{mTNBC}$, are pending.

Immune checkpoint inhibitors are also being investigated for monotherapy, and atezolizumab and pembrolizumab both have shown durable responses but in limited patient subsets. Results from the single-arm atezolizumab monotherapy trial in mTNBC were promising, with an ORR of $26 \%$ and $7 \%$ in the $1 \mathrm{~L}$ and $2 \mathrm{~L}+$ settings, respectively; median DOR was 21 months (range $8+$ to $26+$ months) in the $1 \mathrm{~L}$ setting, and DOR ranged from 3 to $13+$ months in the $2 \mathrm{~L}+$ setting [48]. In KEYNOTE-086, a phase II study of pembrolizumab monotherapy for heavily pretreated mTNBC reported an overall ORR of $5 \%$ in a $2 \mathrm{~L}+$ subset of patients. The median DOR was 6.3 months (range, $1.2+$ to $10.3+$ months), with a median PFS and OS of 2 months and 8.9 months, respectively [49].

\section{PARP inhibitors}

When the NCCN guidelines were updated in 2018 and 2019, after this systematic review was conducted, two poly adenosine diphosphate (ADP) ribose polymerase (PARP) inhibitors, olaparib and talazoparib, were added for the treatment of germline BRCA-mutated HER2negative $\mathrm{MBC}$ [50]. In the recent phase 3 OlympiAD trial of single-agent olaparib versus physician choice chemotherapy as $1 \mathrm{~L}+$ treatment for patients with germline BRCA-mutant and HER2-negative MBC (50\% of patients with $\mathrm{mTNBC}$ ), use of olaparib showed improvement in ORR (60\% vs 29\%) and median PFS (7.0 months vs 4.2 months) compared with chemotherapy [17]. Similarly, the EMBRACA trial of talazoparib versus chemotherapy as a $2 \mathrm{~L}+$ treatment in a similar patient population $(45 \% \mathrm{mTNBC})$ reported that, compared with chemotherapy, talazoparib conferred a significantly higher ORR (62.6\% vs $27.2 \%$; $P<0.001)$ and significantly longer median PFS (8.6 months vs 5.6 months; $P<0.001$ ) (Table 2) [16].

\section{AKT inhibitors}

Addition of AKT inhibitors to chemotherapy is also being investigated as $1 \mathrm{~L}$ treatment for patients with mTNBC. A recent combination trial of the AKT inhibitor ipatasertib plus paclitaxel as $1 \mathrm{~L}$ treatment for mTNBC (LOTUS trial) reported a median PFS of 6.2 months with the ipatasertib combination (vs 4.9 months with the placebo combination; $P=0.037$; Table 2). After a follow-up of 23 months, median OS was 23.1 months with ipatasertib (vs 18.4 months with placebo plus paclitaxel) and the 1-year OS rate increased from 70 to $83 \%$ with the addition of ipatasertib; OS seemed to be independent of PTEN expression status [14, 15]. Furthermore, the AKT inhibitor AZD5363 (capivasertib) is being investigated in combination with paclitaxel in patients with previously untreated mTNBC (PAKT) [51]. After a median follow-up of 18.2 months, PFS and OS were both longer with capivasertib plus paclitaxel than with placebo plus paclitaxel (PFS, 5.9 months vs 4.2 months; OS, 19.1 months vs 12.6 months).

\section{Antibody drug conjugates}

Among ADCs, on February 5, 2016, the FDA granted breakthrough therapy designation to sacituzumab govitecan (IMMU-132) as 3L treatment for mTNBC based on the results of a phase I/II clinical trial, which demonstrated an ORR of $34 \%$, a median PFS of 5.5 months, and a median OS of 12.7 months [52]. In the EMERGE phase II trial with the $3 \mathrm{~L}+\mathrm{mTNBC}$ subpopulation treated with another ADC, glembatumumab vedotin (GV), reporting an ORR of $18 \%$ (vs $0 \%$ for the chemotherapy-treated counterparts), these figures were $40 \%$ and $0 \%$, respectively, for patients with mTNBC overexpressing glycoprotein NMB (gpNMB) [53]. There was a suggestion of possible improvement in survival (PFS and OS) with GV compared with chemotherapy in this population of the EMERGE study (PFS: 3.5 months vs 1.5 months; OS, 10.0 months vs 5.5 months) [53]. However, a recent trial of $\mathrm{GV}$ versus capecitabine in a similar population of patients with gpNMB-overexpressing mTNBC (METRIC) did not meet its primary PFS objective, with no improvement in PFS with GV compared with capecitabine, and no OS benefit [54].

\section{Limitations}

No mTNBC-specific randomized controlled trials directly comparing NCCN-recommended (v1.2016) chemotherapies for the treatment of $\mathrm{MBC}$ were identified in this search, allowing only indirect comparison between studies. Furthermore, no phase III trial studying singleagent chemotherapy for the treatment of mTNBC in any line of therapy was found. Given that results from only one global phase III trial to evaluate combination chemotherapy in mTNBC are available [40], retrospective (and in one case prospective [41]) subgroup analyses of the mTNBC subpopulation from larger phase III $\mathrm{MBC}$ trials and smaller phase II trials, including singlearm trials, were included in this evidence synthesis. Furthermore, for the meta-analysis of $2 \mathrm{~L}+$ chemotherapies, quantitative adjustment for differences in patient characteristics across trials was not feasible because of the paucity of such historical trials. It should also be noted that these clinical trial results are representative of a very select group of patients with mTNBC. Therefore, worse outcomes are likely in the general population of patients, 
many of whom would not meet the stringent eligibility criteria specified in these clinical trials (e.g., exclusion of patients with brain metastases at screening, exclusion of patients with early recurrences in first-line studies).

\section{Conclusions}

Adequately controlled historical data on the treatment of mTNBC are limited, which may be attributed to the lack of therapies specific to mTNBC. Among the available historical data, commonly used chemotherapies have demonstrated limited durability of response, limited survival benefit, and challenging toxicity profiles, suggesting a considerable unmet medical need in mTNBC. The recent approval of the combination of nab-paclitaxel and atezolizumab for the treatment of PD-L1-positive (IC1+) mTNBC is a positive development for a subset of patients with mTNBC ( $41 \%$ by the Ventana PD-L1 [SP142] assay). However, therapeutic regimens that result in improved, sustainable clinical responses and longer survival, along with more manageable safety profiles, are still needed for patients with mTNBC, including those with PD-L1-negative tumors. Ongoing and future studies with immune therapies, targeted agents, and ADCs, either as monotherapy or combination treatment, can provide new opportunities for improved outcomes in patients with this difficult-to-treat BC subtype.

\section{Supplementary information}

Supplementary information accompanies this paper at https://doi.org/10. 1186/s13058-019-1210-4

Additional file 1: Table S1. PubMed search queries.

Additional file 2: Table S2. Cochrane search queries.

Additional file 3: Table S3. Embase search queries.

\begin{abstract}
Abbreviations
1L: First-line; $2 \mathrm{~L}+$ : Second-line or higher; $3 \mathrm{~L}$ : Third-line; ADCs: Antibody drug conjugates; AE: Adverse event; APaT: All patients as treated; BC: Breast cancer; Cl: Confidence interval; DOR: Duration of response; ESOESMO: European School of Oncology-European Society for Medical Oncology; FDA: US Food and Drug Administration; gpNMB: Glycoprotein NMB; GV: Glembatumumab vedotin; MBC: Metastatic breast cancer; mTNBC: Metastatic triple-negative breast cancer; NCCN: National Comprehensive Cancer Network; ORR: Objective response rate; OS: Overall survival; PD-1: Programmed death 1; PD-L1: Programmed death-ligand 1; PFS: Progression-free survival; TNBC: Triple-negative breast cancer
\end{abstract}

\section{Acknowledgements}

The authors thank the study 301 research team. Medical writing and/or editorial assistance was provided by Amy McQuay, PhD, of the ApotheCom pembrolizumab team (Yardley, PA, USA). This assistance was funded by Merck Sharp \& Dohme Corp., a subsidiary of Merck \& Co., Inc., Kenilworth, NJ, USA.

\section{Authors' contributions}

$\mathrm{CHL}, \mathrm{VK}$, and $\mathrm{ML}$ conceived and designed the analysis; $\mathrm{CHL}, \mathrm{GA}$, and $\mathrm{ML}$ collected the data; $\mathrm{CHL}, \mathrm{GA}$, and $\mathrm{ML}$ analyzed the data; and $\mathrm{CHL}, \mathrm{VK}, \mathrm{GA}$, and $\mathrm{ML}$ interpreted the data. All authors were involved in the drafting, critical review, and approval of the final manuscript and the decision to submit for publication.

\section{Funding}

Funding for this research was provided by Merck Sharp \& Dohme Corp., a subsidiary of Merck \& Co., Inc., Kenilworth, NJ, USA.

Availability of data and materials Not applicable.

Ethics approval and consent to participate Not applicable.

Consent for publication

$\mathrm{CHL}, \mathrm{VK}, \mathrm{GA}$, and $\mathrm{ML}$ have consented to the publication of this manuscript.

\section{Competing interests}

CHL, VK, GA, and ML are employees of Merck Sharp \& Dohme Corp., a subsidiary of Merck \& Co., Inc., Kenilworth, NJ, USA.

Received: 24 January 2019 Accepted: 15 October 2019

Published online: 16 December 2019

\section{References}

1. Siegel RL, Miller KD, Jemal A. Cancer statistics, 2018. CA Cancer J Clin. 2018; 68:7-30.

2. Bauer KR, Brown M, Cress RD, Parise CA, Caggiano V. Descriptive analysis of estrogen receptor (ER)-negative, progesterone receptor (PR)-negative, and HER2-negative invasive breast cancer, the so-called triple-negative phenotype: a population-based study from the California Cancer Registry. Cancer. 2007:109:1721-8.

3. Carey LA, Perou CM, Livasy CA, Dressler LG, Cowan D, et al. Race, breast cancer subtypes, and survival in the Carolina Breast Cancer Study. JAMA. 2006;295:2492-502.

4. Dent R, Trudeau M, Pritchard KI, Hanna WM, Kahn HK, et al. Triple-negative breast cancer: clinical features and patterns of recurrence. Clin Cancer Res. 2007:13:4429-34.

5. National Comprehensive Cancer Network. NCCN clinical practice guidelines in oncology (NCCN guidelines): breast cancer (Version 1.2019). Accessed 8 July 2019.

6. Cardoso F, Senkus E, Costa A, Papadopoulos E, Aapro M, et al. 4th ESOESMO International Consensus Guidelines for Advanced Breast Cancer (ABC 4). Ann Oncol. 2018;29:1634-57.

7. Zeichner SB, Terawaki H, Gogineni K. A review of systemic treatment in metastatic triple-negative breast cancer. Breast Cancer. 2016;10:25-36.

8. Piccart-Gebhart MJ, Burzykowski T, Buyse M, Sledge G, Carmichael J, et al. Taxanes alone or in combination with anthracyclines as first-line therapy of patients with metastatic breast cancer. J Clin Oncol. 2008;26:1980-6.

9. Twelves C, Cortes J, Vahdat L, Olivo M, He Y, Kaufman PA, Awada A. Efficacy of eribulin in women with metastatic breast cancer: a pooled analysis of two phase 3 studies. Breast Cancer Res Treat. 2014;148:553-61.

10. Schmid P, Adams S, Rugo HS, Schneeweiss A, Barrios $\mathrm{CH}$, et al. Atezolizumab and nab-paclitaxel in advanced triple-negative breast cancer. N Engl J Med. 2018:379:2108-21.

11. TECENTRIQ (atezolizumab) injection, for intravenous use [prescribing information]. South San Francisco, CA, USA: Genentech, Inc.; 2019.

12. National Comprehensive Cancer Network. NCCN clinical practice guidelines in oncology (NCCN guidelines): breast cancer Version 1.2016). Accessed 8 July 2019.

13. Pivot X, Marme F, Koenigsberg R, Guo M, Berrak E, Wolfer A. Pooled analyses of eribulin in metastatic breast cancer patients with at least one prior chemotherapy. Ann Oncol. 2016;27:1525-31.

14. Dent R, Seock-Ah IM, Espie M, Blau S, Tan AR, et al. Overall survival (OS) update of the double-blind placebo (PBO)-controlled randomized phase 2 LOTUS trial of first-line ipatasertib (IPAT) + paclitaxel (PAC) for locally advanced/metastatic triple-negative breast cancer (mTNBC). J Clin Oncol. 2018;36(15_suppl):1008.

15. Kim SB, Dent R, Im SA, Espie M, Blau S, et al. Ipatasertib plus paclitaxel versus placebo plus paclitaxel as first-line therapy for metastatic triplenegative breast cancer (LOTUS): a multicentre, randomised, double-blind, placebo-controlled, phase 2 trial. Lancet Oncol. 2017;18:1360-72.

16. Litton JK, Rugo HS, Ettl J, Hurvitz SA, Gonçalves A, et al. Talazoparib in patients with advanced breast cancer and a germline BRCA mutation. $N$ Engl J Med. 2018;379:753-63. 
17. Robson M, Im SA, Senkus E, Xu B, Domchek SM, et al. Olaparib for metastatic breast cancer in patients with a germline BRCA mutation. N Engl J Med. 2017;377:523-33.

18. Robson ME, Tung N, Conte P, Im SA, Senkus E, et al. OlympiAD final overall survival and tolerability results: Olaparib versus chemotherapy treatment of physician's choice in patients with a germline BRCA mutation and HER2negative metastatic breast cancer. Ann Oncol. 2019;30(4):558-66.

19. Tutt A, Tovey H, Cheang MCU, Kernaghan S, Kilburn L, et al. Carboplatin in BRCA1/2-mutated and triple-negative breast cancer BRCAness subgroups: the TNT Trial. Nat Med. 2018;24:628-37.

20. DerSimonian R, Laird N. Meta-analysis in clinical trials. Control Clin Trials. 1986;7:177-88.

21. Liberati A, Altman DG, Tetzlaff J, Mulrow C, Gotzsche PC, et al. The PRISMA statement for reporting systematic reviews and meta-analyses of studies that evaluate health care interventions: explanation and elaboration. PLoS Med. 2009;6:e1000100

22. Vermorken JB, Herbst RS, Leon X, Amellal N, Baselga J. Overview of the efficacy of cetuximab in recurrent and/or metastatic squamous cell carcinoma of the head and neck in patients who previously failed platinumbased therapies. Cancer. 2008;112:2710-9.

23. Aftimos P, Polastro L, Ameye $L$, Jungels $C$, Vakili J, et al. Results of the Belgian expanded access program of eribulin in the treatment of metastatic breast cancer closely mirror those of the pivotal phase III trial. Eur J Cancer. 2016;60:117-24

24. Awada A, Bondarenko IN, Bonneterre J, Nowara E, Ferrero JM, et al. A randomized controlled phase II trial of a novel composition of paclitaxel embedded into neutral and cationic lipids targeting tumor endothelial cells in advanced triple-negative breast cancer (TNBC). Ann Oncol. 2014;25:824-31.

25. Baselga J, Gomez P, Greil R, Braga S, Climent MA, et al. Randomized phase I study of the anti-epidermal growth factor receptor monoclonal antibody cetuximab with cisplatin versus cisplatin alone in patients with metastatic triple-negative breast cancer. J Clin Oncol. 2013;31:2586-92.

26. Brufsky A, Valero V, Tiangco B, Dakhil S, Brize A, et al. Second-line bevacizumab-containing therapy in patients with triple-negative breast cancer: subgroup analysis of the RIBBON-2 trial. Breast Cancer Res Treat 2012;133:1067-75.

27. Isakoff SJ, Mayer EL, He L, Traina TA, Carey LA, et al. TBCRC009: a multicenter phase II clinical trial of platinum monotherapy with biomarker assessment in metastatic triple-negative breast cancer. J Clin Oncol. 2015;33:1902-9.

28. Miles DW, Dieras V, Cortes J, Duenne AA, Yi J, O'Shaughnessy J. First-line bevacizumab in combination with chemotherapy for HER2-negative metastatic breast cancer: pooled and subgroup analyses of data from 2447 patients. Ann Oncol. 2013;24:2773-80.

29. Perez EA, Awada A, O'Shaughnessy J, Rugo HS, Twelves C, et al. Etirinotecan pegol (NKTR-102) versus treatment of physician's choice in women with advanced breast cancer previously treated with an anthracycline, a taxane, and capecitabine (BEACON): a randomised, open-label, multicentre, phase 3 trial. Lancet Oncol. 2015;16:1556-68.

30. Pivot XB, Li RK, Thomas ES, Chung HC, Fein LE, et al. Activity of ixabepilone in oestrogen receptor-negative and oestrogen receptor-progesterone receptor-human epidermal growth factor receptor 2-negative metastatic breast cancer. Eur J Cancer. 2009:45:2940-6.

31. Sparano JA, Vrdoljak E, Rixe O, Xu B, Manikhas A, et al. Randomized phase III trial of ixabepilone plus capecitabine versus capecitabine in patients with metastatic breast cancer previously treated with an anthracycline and a taxane. J Clin Oncol. 2010;28:3256-63.

32. Tredan O, Campone M, Jassem J, Vyzula R, Coudert B, et al. Ixabepilone alone or with cetuximab as first-line treatment for advanced/metastatic triple-negative breast cancer. Clin Breast Cancer. 2015;15:8-15.

33. von Minckwitz G, Puglisi F, Cortes J, Vrdoljak E, Marschner N, et al. Bevacizumab plus chemotherapy versus chemotherapy alone as second-line treatment for patients with HER2-negative locally recurrent or metastatic breast cancer after first-line treatment with bevacizumab plus chemotherapy (TANIA): an open-label, randomised phase 3 trial. Lancet Oncol. 2014;15:1269-78.

34. Brodowicz T, Lang I, Kahan Z, Greil R, Beslija S, et al. Selecting first-line bevacizumab-containing therapy for advanced breast cancer: TURANDOT risk factor analyses. Br J Cancer. 2014;111:2051-7.

35. Dieras V, Campone M, Yardley DA, Romieu G, Valero V, et al. Randomized, phase II, placebo-controlled trial of onartuzumab and/or bevacizumab in combination with weekly paclitaxel in patients with metastatic triplenegative breast cancer. Ann Oncol. 2015;26:1904-10.

36. Fan Y, Xu BH, Yuan P, Ma F, Wang JY, et al. Docetaxel-cisplatin might be superior to docetaxel-capecitabine in the first-line treatment of metastatic triple-negative breast cancer. Ann Oncol. 2013;24:1219-25.

37. Halim IIA, El-Sadda W, El-Ebrashy M, El Ashry M. Phase II study of weekly paclitaxel and carboplatin followed by oral navelbine in patients with triple negative metastatic/recurrent breast cancer previously treated with adjuvant anthracycline and taxotere. J Clin Oncol. 2016; 34(15_suppl):e12557.

38. Li Q, Li Q, Zhang P, Yuan P, Wang J, et al. A phase II study of capecitabine plus cisplatin in metastatic triple-negative breast cancer patients pretreated with anthracyclines and taxanes. Cancer Biol Ther. 2015;16:1746-53.

39. Liao Y, Fan Y, Wan Y, Li J, Peng L. Acceptable but limited efficacy of capecitabine-based doublets in the first-line treatment of metastatic triplenegative breast cancer: a pilot study. Chemotherapy. 2013;59:207-13.

40. O'Shaughnessy J, Schwartzberg L, Danso MA, Miller KD, Rugo HS, et al. Phase III study of iniparib plus gemcitabine and carboplatin versus gemcitabine and carboplatin in patients with metastatic triple-negative breast cancer. J Clin Oncol. 2014;32:3840-7.

41. Rugo HS, Barry WT, Moreno-Aspitia A, Lyss AP, Cirrincione C, et al. Randomized phase III trial of paclitaxel once per week compared with nanoparticle albumin-bound nab-paclitaxel once per week or ixabepilone with bevacizumab as first-line chemotherapy for locally recurrent or metastatic breast cancer: CALGB 40502/NCCTG N063H (Alliance). J Clin Oncol. 2015;33:2361-9.

42. Robert NJ, Dieras V, Glaspy J, Brufsky AM, Bondarenko I, et al. RIBBON-1: randomized, double-blind, placebo-controlled, phase III trial of chemotherapy with or without bevacizumab for first-line treatment of human epidermal growth factor receptor 2-negative, locally recurrent or metastatic breast cancer. J Clin Oncol. 2011;29:1252-60.

43. Carey LA, Rugo HS, Marcom PK, Mayer EL, Esteva FJ, et al. TBCRC 001: randomized phase $\|$ study of cetuximab in combination with carboplatin in stage IV triple-negative breast cancer. J Clin Oncol. 2012;30:2615-23.

44. Duda DG, Ziehr DR, Guo H, Ng M, Barry WT, et al. Effect of cabozantinib treatment on circulating immune cell populations in patients with metastatic triple-negative breast cancer (TNBC). J Clin Oncol. 2016;34(15_suppl):1093.

45. Hu X, Zhang J, Xu B, Jiang Z, Ragaz J, et al. Multicenter phase II study of apatinib, a novel VEGFR inhibitor in heavily pretreated patients with metastatic triple-negative breast cancer. Int J Cancer. 2014;135:1961-9.

46. Tolaney SM, Tan S, Guo H, Barry W, Van AE, et al. Phase II study of tivantinib (ARQ 197) in patients with metastatic triple-negative breast cancer. Investig New Drugs. 2015;33:1108-14.

47. Tutt A, Robson M, Garber JE, Domchek SM, Audeh MW, et al. Oral poly (ADP-ribose) polymerase inhibitor olaparib in patients with BRCA1 or BRCA2 mutations and advanced breast cancer: a proof-of-concept trial. Lancet. 2010:376:235-44.

48. Emens LA, Braiteh FS, Cassier P, Delord J-P, Eder JP, et al. Inhibition of PD-L1 by MPDL3280A leads to clinical activity in patients with metastatic triple-negative breast cancer (TNBC). Cancer Res. 2015;75(15_ suppl):2859.

49. Adams S, Schmid P, Rugo HS, Winer EP, Loirat D, et al. Phase 2 study of pembrolizumab (pembro) monotherapy for previously treated metastatic triple-negative breast cancer (mTNBC): KEYNOTE-086 cohort A. J Clin Oncol. 2017;35(15_suppl):1008.

50. National Comprehensive Cancer Network. NCCN clinical practice guidelines in oncology (NCCN guidelines): breast cancer (Version 1.2018). Accessed 8 July 2019

51. Schmid P, Abraham J, Chan S, Wheatley D, Brunt M, et al. AZD5363 plus paclitaxel versus placebo plus paclitaxel as first-line therapy for metastatic triple-negative breast cancer (PAKT): a randomised, double-blind, placebocontrolled, phase II trial. J Clin Oncol. 2018;36(15_suppl):1007.

52. Bardia A, Vahdat L, Diamond J, Kalinsky K, O'Shaughnessy J, et al. Abstract GS1-07: Sacituzumab govitecan (IMMU-132), an anti-Trop-2-SN-38 antibodydrug conjugate, as $\geq 3$ rd-line therapeutic option for patients with relapsed/ refractory metastatic triple-negative breast cancer (mTNBC): efficacy results [abstract]. Cancer Res. 2018;78(suppl 4):Abstract GS1-07.

53. Yardley DA, Weaver R, Melisko ME, Saleh MN, Arena FP, et al. EMERGE: a randomized phase II study of the antibody-drug conjugate glembatumumab vedotin in advanced glycoprotein NMB-expressing breast cancer. J Clin Oncol. 2015;33:1609-19. 
54. Vahdat LT, Forero-Torres A, Schmid P, Blackwell K, Telli ML, et al. A randomized international phase $2 \mathrm{~b}$ study of the antibody-drug conjugate (ADC) glembatumumab vedotin (GV) in gpNMB-overexpressing, metastatic, triplenegative breast cancer (mTNBC). J Clin Oncol. 2019;79(4_suppl):P6-20 01.

\section{Publisher's Note}

Springer Nature remains neutral with regard to jurisdictional claims in published maps and institutional affiliations.

Ready to submit your research? Choose BMC and benefit from:

- fast, convenient online submission

- thorough peer review by experienced researchers in your field

- rapid publication on acceptance

- support for research data, including large and complex data types

- gold Open Access which fosters wider collaboration and increased citations

- maximum visibility for your research: over $100 \mathrm{M}$ website views per year

At $\mathrm{BMC}$, research is always in progress.

Learn more biomedcentral.com/submissions 